\title{
Assessment System of Community Road based on the Spatial Dimension
}

\author{
Yuchen Huang \\ North China Electric Power University, Beijing, 102206 \\ alanncepu@foxmail.com
}

Keywords: Open community; Traffic congestion; Rationality; Static assessment system

\begin{abstract}
The "certain opinions on further strengthening the construction of urban planning management work" published by the State Council was proposed "The residential Community has been built and the unit compound is being open", it caused widespread concern of public opinion. Today, under the plight of urban traffic congestion in China, optimizing the road network structure is a wise decision in order to alleviate the traffic. In order to measure the rationality of that policy, this study had established the static assessment system based on spatial dimension to explore the effect of Community open to the surrounding roads in Mathematical Modeling.
\end{abstract}

\section{Background}

The "closed" Community building mode was divided the city into many enclosed unit. In resources increasingly tense and increasingly populated city, it obstructed the traffic of the city, leading that the network structure cannot connect each unit and the resources cannot be shared.

The party central committee and the state council recently issued " certain opinions on further strengthening the construction of urban planning management work ", which mentioned that "no more enclosed residential compounds will be built in principle, at the same time, existing residential and corporate compounds will gradually open up, the interior roads can be put into public use, solve the problem of traffic road network, promote the economical utilization of land, set up the city road layout concept of "narrow road, dense road network", construct the gradation reasonable road network system which made up of expressway, primary and secondary roads."

The topic on whether this method is reasonable or not has attracted wide attention and discussion. To research the open community's impact on the surrounding roads, it is necessary to establish a comprehensive assessment index system, which can numerically compare the condition of the community before and after open.

\section{Problem Analysis}

Considering that the road capacity closely related to the different space, both community interior and the surrounding roads are static systems, this paper established a static assessment system based on spatial dimension".

Spatial dimension can be calculated according to the relevant data before the implementation of the open community policy. According to some data related to spatial distribution of the community, this model introduces three indexes, including "road network density", " road network connection degree" and "per capita road length". 


\section{Symbol Description}

Table 1

\begin{tabular}{|c|c|c|}
\hline Designation & Symbols & Unit \\
\hline Road network density & $\mathrm{M}$ & $\mathrm{km} / \mathrm{km}^{2}$ \\
\hline Total length of road & $\mathrm{L}$ & $\mathrm{km}$ \\
\hline Per capita roads length & $\mathrm{L}^{6}$ & $\mathrm{~km}$ \\
\hline Total area & $\mathrm{S}$ & $\mathrm{km}^{2}$ \\
\hline Network connection degree & $\mathrm{D}$ & \\
\hline Sides & $\alpha$ & \\
\hline Nodes & $\mathrm{N}$ & \\
\hline Urban non-agricultural population & $\mathrm{Q}$ & \\
\hline
\end{tabular}

\section{Static Assessment System Based On Spatial Dimension}

\section{Local Assumptions}

We assume that the road capacity of spatial dimension is only related to the "road network density", " network connection degree" and "per capita roads length".

Community open just increased the contact between the roads, and it did not influence the direction of each road in community and surrounding area.

After the opening of community, the population and total area were the same as before.

All the data used in the calculation process was accurate and reliable.

\section{Establishment of Assessment System}

These three indicators are calculated as follows:

(1) road network density $=$ total length of all roads in a given area / total area, unit as $\mathrm{km} / \mathrm{km}^{2}$, namely

$$
M=\frac{L}{S}
$$

(2) network connection degree $=$ the sum of the number of nodes edges $/$ the number of nodes, namely

$$
\mathrm{D}=\frac{\mathrm{a}}{\mathrm{N}}
$$

(3) per capita roads length = city road length / urban non-agricultural population, namely

$$
\mathrm{L}^{\prime}=\frac{\mathrm{L}}{\mathrm{Q}}
$$

\section{Study Case}

The following table shows the data in an area:

Table 2

\begin{tabular}{|c|c|c|c|c|c|}
\hline & $\begin{array}{c}\text { Total area } \\
\left(\mathrm{km}^{2}\right)\end{array}$ & $\begin{array}{c}\text { Total length } \\
\text { of road } \\
(\mathrm{km})\end{array}$ & Nods & Sides & $\begin{array}{c}\text { Urban } \\
\text { non-agricultural } \\
\text { population }\end{array}$ \\
\hline $\begin{array}{c}\text { Before } \\
\text { open }\end{array}$ & 2.7 & 5.8 & 9 & 6 & 42600 \\
\hline $\begin{array}{c}\text { After } \\
\text { open }\end{array}$ & 2.7 & 10.816 & 18 & 13 & 42600 \\
\hline
\end{tabular}


Then, apply the data from above table to the formula of the three indexes.

The index's variation was defined as a ratio of the data before and after community open:

Table 3

\begin{tabular}{|c|c|c|c|}
\hline & $\begin{array}{c}\text { road network } \\
\text { density }\end{array}$ & $\begin{array}{c}\text { Network } \\
\text { connection degree }\end{array}$ & $\begin{array}{c}\text { per capita roads } \\
\text { length }(\mathrm{m})\end{array}$ \\
\hline Before open & 2.14815 & 0.66667 & 0.13615 \\
\hline After open & 4.00593 & 0.72222 & 0.25390 \\
\hline ratio & 0.53624 & 0.92308 & 0.53623 \\
\hline
\end{tabular}

It was not necessary to standardize each variable, since the model uses the same ratio of indexes in calculation.

Table 4

\begin{tabular}{|c|c|c|c|}
\hline & $\begin{array}{c}\text { road network } \\
\text { density }\end{array}$ & $\begin{array}{c}\text { Network } \\
\text { connection degree }\end{array}$ & $\begin{array}{c}\text { per capita roads } \\
\text { length }\end{array}$ \\
\hline road network density & 1 & 0.33 & 0.50 \\
\hline $\begin{array}{c}\text { Network connection } \\
\text { degree }\end{array}$ & 3 & 1 & 0.50 \\
\hline per capita roads length & 2 & 2 & 1 \\
\hline
\end{tabular}

Eventually, multiply the value of each index by the weight of itself, we can get the final score of each road, namely the score of the static assessment system in this area, 1.604329502.

\section{Assessment of Model}

In the process of establishing the assessment system, this paper set up a model from the perspective of static assessment system, which makes the calculation and comparison of the assessment system easier.

This assessment indexes above did not take the traffic speed and traffic delay into consideration, so the assessment was not comprehensive.

The road assessment indexes did not refer to the safety of the vehicle and the freedom of the vehicle.

\section{Reasonable Suggestions about the Opening Community}

Firstly, the communities with a lot of people should not be open, because the pedestrians will become an obstacle for the vehicles. Although the road network will be more compact after community open, it will decline the traffic efficiency. Additionally, the opening of the community will bring a great danger to pedestrians.

Secondly, some road networks of community are compact enough, and the matching between trunk roads, primary and secondary branches is appropriate, even though a community is closed, the traffic around it is not crowd. There are no significant improvements on urban road traffic after the implementation of this policy. We suggest that don't open this community base on the economic costs and possible social problems.

Thirdly, if a community has a big traffic flow, it means that this community is located in a flourishing area, and all aspects of the city are developing rapidly. Both opening community and traffic congestion have economic costs. So we not only have to consider fuel losses and environmental pollution, but also have to consider the time loss and efficiency costs, which hinder the development of the city. Therefore, the opening of such a community has both advantages and disadvantages to the economy, so we should consider the condition more comprehensively.

Fourthly, for the open community, it is suggested that the government should establish 
reasonable traffic rules at the junction when necessary, such as setting traffic lights, building some pedestrians, and setting vehicle signs and so on. It can make the pedestrians and vehicles getting along better, reduce the accident rate, avoid congestion caused by non-standard traffic within the community, and avoid the waste of time caused by cutting in line.

Finally, the residential community and the unit compound should be opened gradually. For the larger community, the government should regard the needs of the entire road network planning, as well as vehicle flow, passenger flow and economy. It is a wise way to open the community locally, and converted it into a half open area.

\section{References:}

[1] S.K. Si, X.Q. Sun. Mathematical modeling algorithms and Applications [M]. National Defense Industry Press. Beijing: 2015.

[2] X.P. Li .Study on urban traffic congestion Countermeasures of closed area traffic opening [D]. Changsha University of Science \& Technology. Changsha: 2014

[3] X. Zhao. Study on optimization method of urban traffic micro circulation network with multiple constraints [D]. Jilin University: 2015.

[4] J.P. Zhou. Microcirculation theory and branch traffic [J]. Urban transportation 2010, 08(3):41-49.

[5] H.Z. Huang. Optimization theory and method of urban road traffic micro circulation system [D]. Zhongnan University: 2009

[6] M. Zhong. Study on Optimization of urban traffic micro circulation network based on Sustainable Development [D]. Southwest Jiaotong University. Shanghai: 2013.

[7] B.G. Hang, W. S et al. Traffic engineering foundation [M]. China building industry press .Beijing: 1990.

[8] D.M. Li, W.Q. Li, Calculation method of road capacity. Journal of Henan University. 2002, 32(2):24-27.

[9] ] http://www.gov.cn/zhengce/2016-02/21/content_5044367.htm

[10]J.P. Zhou. Theory and branch traffic microcirculation [J]. Urban transportation, 2010, 08(3):41-49. 